\title{
Criação de sentido em oficinas de narrativas de viagem
}

\author{
Creating Sense in Travel Narrative Workshops \\ Creación de significado en los talleres de narrativa de viajes
}

\author{
Júlia Fonseca de Castro \\ Universidade Federal de Minas Gerais, Programa de Pós-graduação em Geografia: \\ Organização do Espaço \\ juliafcastro@gmail.com | https://orcid.org/0000-0003-0797-5698
}

\section{Resumo}

Relato de duas oficinas desenvolvidas com público de estudantes heterogêneo, a partir de estímulos diferentes, e com o objetivo comum de compreensão dos sentidos atribuídos ao ato de viajar por meio de relatos (orais e escritos). 0 primeiro grupo foi integrado por cerca de 45 pessoas, 40 alunos dos $1^{\circ}, 2^{\circ}$ e $3^{\circ}$ anos do ensino secundário, além de professores da Escola Casa Viva (Belo Horizonte/Minas Gerais/Brasil). O segundo grupo foi composto por aproximadamente 40 alunos graduandos em Turismo e em Geografia pela Universidade de Coimbra (Coimbra/ Portugal). Ambas as oficinas aconteceram em 2017 e incluíram palestra e atividade prática. Os resultados das oficinas indicam que os participantes experimentaram criativamente a proposta e produziram sentidos para o viajar desviados da lógica do mercado turístico, do jornalismo de viagem e, em geral, do senso comum.

Palavras-chave: Viagem. Relato de viagem. Narrativa. Representação. Criação de Sentido.

\begin{abstract}
Report of two workshops developed with a heterogeneous student audience, based on different stimulus, and with the common objective of understanding the meanings attributed to the act of traveling through reports (oral and written). The first group was made up of about 45 people, 40 students from the 1st, 2nd and 3rd years of secondary education, in addition to teachers from the Casa Viva School (Belo Horizonte/Minas Gerais/Brasil). The second group was composed of approximately 40 undergraduate students in Tourism and Geography from the University of Coimbra (Coimbra / Portugal). Both workshops took place in 2017 and included a lecture and practical activity. The results of the workshops indicate that the participants creatively experimented with the proposal and produced meanings for travel deviated from the logic of the tourist market, travel journalism and, in general, common sense.

Keywords: Travel. Travel Report. Narrative. Representation. Creating Meaning.
\end{abstract}

\section{Resumen}

Informe de dos talleres desarrollados con público estudiantil heterogéneo, basado en diferentes estímulos, y con el objetivo común de comprender los significados atribuidos al acto de transitar a traves de informar (oral y escrito). El primer grupo estaba formado por 45 personas, 40 alumnos de 1ํ, 2ำ y 3 de educación secundaria, además de profesores de la Escuela Casa Viva (Belo Horizonte / Minas Gerais / Brasil). El segundo grupo estaba compuesto por aproximadamente 40 estudiantes de pregrado en Turismo y Geografía de la Universidad de Coimbra (Coimbra / Portugal). Ambos talleres tuvieron lugar en 2017 e incluyeron una conferencia y una actividad práctica. Los resultados de los talleres indican que los participantes experimentaron creativamente con la propuesta y produjeron significados para viajar desviados de la lógica del mercado turístico, del periodismo de viajes y, en general, del sentido común.

Palabras clave: Viajar. Informe de viaje. Narrativa. Representación. Creación de sentido

Artigo recebido em: 06/10/2020 | Aprovado em: 16/03/2021 | Publicado em: 01/08/2021

Como citar:

CASTRO, Julia Fonseca de. Criação de sentido em oficinas de narrativas de viagem. Pesquisa e Debate em Educação, Juiz de Fora: UFJF, v. 11, n. 2, p. 01-16, e32502, jul./dez. 2021. ISSN 2237-9444. DOI: https://doi.org/10.34019/2237-9444.2021.v11.32502. 


\section{Introdução}

O presente relato foi desenvolvido em período em que me dedicava a uma tese de doutorado em Geografia Humana, na Universidade Federal de Minas Gerais (UFMG), com o tema das narrativas de viagem. Busquei, em diversos gêneros textuais, aspectos para refletir sobre a relação entre viagem e narrativa, contemplando, também, a oralidade. A partir de convites para palestras com o tema viagem, literatura e experiência, iniciei uma proposta de transformação de tais intervenções em diálogos, extrapolando o formato de palestra e propondo a realização de oficinas de escrita de relatos de viagem. Parte dos meus objetivos consistia em conduzir o diálogo com grupos de estudantes a partir de reflexões previamente realizadas e abrir espaço para que os envolvidos expusessem as viagens que realizaram e refletissem sobre elas.

As oportunidades aconteceram em 2017, mediante dois convites: o primeiro foi feito pelo Instituto Casa Viva (Casa Viva Educação e Cultura), escola primária e secundária localizada em Belo Horizonte (MG/Brasil); o segundo convite foi feito pelo professor orientador do estágio-sanduíche que realizei na Universidade de Coimbra, Portugal.

O desenvolvimento de oficinas permitiu refletir sobre as representações criadas por um público de adolescentes e jovens graduandos. Tais representações tangenciam a dimensão da sensibilidade com relação à vivência da mobilidade e da alteridade cultural (em amplos termos), além de expressarem a busca por um senso de coerência que envolve o autoquestionamento sobre a identidade pessoal na relação estabelecida com os lugares e com as culturas.

Os grupos envolvidos, ainda que diversos, podem ser categorizados como estudantes, em razão do vínculo com as instituições de ensino e pelo fato de as palestras terem acontecido em espaços formais de ensino e aprendizagem. 0 primeiro grupo integrou cerca de 45 pessoas, 40 alunos do $1^{\circ}, 2^{\circ}$ e $3^{\circ}$ anos do ensino secundário, além de professores, e o segundo, cerca de 40 alunos graduandos em Turismo e Geografia pela Universidade de Coimbra. As apresentações orais que realizei foram adaptadas de modo a tentar estimular a participação dos envolvidos e a contribuir para a reflexão.

\section{Desenvolvimento}

\subsection{Ler e escrever a viagem: experimentações no Instituto Casa Viva}

A intervenção no Instituto Casa Viva compreendeu a participação em seminário que ocorre periodicamente na escola, a partir do convite de profissionais de diversas áreas. Criei uma proposta de seminário prático, que foi aprovada pelo núcleo pedagógico. Com a intenção de despertar o interesse dos jovens estudantes, preparei uma abordagem ao tema das viagens que privilegiou a dimensão imagética e foi referenciada por livros de viajantes que percorreram Minas Gerais e também por personagens e autores cujas obras são identificadas como literatura juvenil.

O seminário ocorreu como um debate coletivo com participação ativa dos alunos. O momento da atividade de escrita foi expandido para uma prática ampla de representações que compreendeu desenhos (criados individualmente e coletivamente), poemas (escritos e declamados) e textos no formato relato de viagem. A oralidade e o diálogo foram a tônica do momento compartilhado com os adolescentes. 
Por meio da projeção de imagens, conduzi o diálogo com os adolescentes abordando incialmente o conceito de viagem como experiência típica. Compartilhei algumas imagens de elementos básicos relacionados à ideia de viagem: aviões decolando em aeroportos, trens e carros nas estradas; malas com adesivos de diversos lugares colados na parte externa; pessoas caminhando na estrada com mochila às costas; lugares paradisíacos com areia branca, mar azul e cadeiras de praia; famílias e casais ao ar livre na praia. Perguntei a eles sobre as viagens mais importantes que haviam vivido.

Dentre as participações iniciais, a mais generosa foi a de um aluno que contou sobre a sensação de deslocamento causada por estar longe de casa, citando viagens realizadas à casa dos avós em uma cidade do interior do estado de Minas Gerais, em uma área rural.

O relato desse aluno contemplou a sensação de se sentir diferente, explicando aspectos da mudança geral ativada pela viagem e que lhe trazem a sensação de estranhamento: os móveis, o clima, as atividades, o tempo, a comida, a convivência com outras pessoas, tudo é alterado, "fica diferente". Destaca-se, nesse relato, que a alteridade da viagem é caracterizada a partir do espaço interior da casa - móveis, atividades, comida - e da distância percorrida, que permite alcançar outro lugar, essa cidade do interior. Não é exatamente o percurso a parte mais destacada das viagens desse aluno, bem como não são as descrições do mundo "exterior": imagem que abriga cidades, paisagens, aeroportos internacionais.

No primeiro relato citado, o domínio das relações sociais também foi lembrado como parte da vivência de viagem: a convivência com outras pessoas. "Quando viajamos, as relações sociais se alteram, mesmo que estejamos viajando dentro do mesmo país que moramos", concluiu o aluno. "As diferenças entre culturas ficam mais claras quando estamos em um lugar que apresenta cultura diferente do lugar onde vivemos".

Uma viagem promovida pela escola para uma comunidade quilombola foi mencionada por um professor presente, o qual se lembrou de debates subsequentes, com ênfase no tema tradições culturais, realizados com os alunos. Destaca-se, na primeira participação, o esforço do estudante em organizar determinadas percepções com conceitos, tais como o de relações sociais e o de cultura, motivado, talvez, pelos debates anteriores que envolveram o grupo. De todo modo, ressalta-se, no discurso dele, a elaboração sobre a sensação de alteridade cultural relacionada ao espaço sociocultural do interior de Minas Gerais, do ambiente doméstico e dos espaços de convívio social proporcionados pelo deslocamento vivenciado.

A primeira participação foi concluída com a menção de alguns efeitos ou resultados de viagem. Com um semblante tranquilo, o aluno expressou a sensação de mudança que o toma quando ele retorna de uma viagem. Disse que, ao voltar para casa, sente-se convidado a mudar, a se transformar, "fica com vontade de ser diferente quando retorna da viagem, sente-se renovado e animado". Assim organizou o discurso, refletindo sobre a viagem como estímulo à mudança, ou melhor, ao desejo de mudança e de transformação. 
Quando indagados a respeito das diferenças entre viagens resultantes de modos distintos de se viajar, sejam relacionados aos meios de transporte utilizados, às companhias de viagem - ou à viagem que se faz desacompanhado -, sejam relacionados aos objetivos pretendidos e ao formato geral de uma viagem, os alunos contribuíram, diversificando a ideia de viagem a partir das próprias experiências.

Dentre as participações, destaco a fala, desenquadrada do senso comum, de uma aluna que disse viajar com o pai constantemente, de modo pouco planejado: "Ele apenas compra a passagem e reserva o hotel para o primeiro dia, mas depois a gente não tem ideia do que vamos fazer". Disse que eles não pesquisam quase nada sobre o lugar e a região que irão visitar, pois gostam de chegar e decidir a programação à medida que os dias passam. "Eu gosto desse modo de viajar, mas existem desvantagens, como chegar em algum lugar em que a temperatura está baixa e estar sem roupas adequadas", contou.

Segui com a apresentação declamando um poema, Poema Transitório (2006), de Mário Quintana, e trechos do Livro do Desassossego (2002 [1982]), de Fernando Pessoa, em que o sentido da viagem é explorado, e comentei sobre as etapas da viagem como movimento cíclico que inclui partida, percurso, chegada e, também, retorno ao lar. Abordei os significados de errância e de travessia e estimulei a reflexão acerca do movimento em relação ao espaço interior, psíquico e subjetivo, que permite o afastamento do cotidiano e a desestabilização do viajante, e do movimento externo, de alcance e vivência nos lugares.

Sobre a importância da literatura, mais precisamente das narrativas/histórias de viagem, destaquei duas: a Odisseia (1957), do herói Ulisses (da Odisseia), e a de Marco Polo, no Livro das Maravilhas (1999). Discuti as características das duas viagens nas quais um dos viajantes - Ulisses - é um herói que tenta retornar ao lar após vencer uma guerra e enfrenta vários desafios para conseguir recuperar o lugar que é dele no reino; e o outro é um mercador - Marco Polo -, que viaja para a Ásia e depois conta as maravilhas vistas, baseando-se em um olhar descritivo. Sugeri que os traços principais desses dois viajantes auxiliam a refletir sobre o discurso comum produzido sobre viagem. Compartilhei a crítica ao discurso sobre viagem que visa promover um tipo de mobilidade que é produzido à imagem do movimento em forma de tour, de itinerário circular, que inclui o retorno ao lar (tal como Ulisses), além de enfatizar a questão visual e imagética (o olhar descritivo/testemunhal).

Nesse momento, uma aluna relatou a experiência que viveu no exterior, em um país europeu, criticando o comportamento da maioria dos turistas que percorre praças, ruas e museus de modo aparentemente mecanizado, com pressa e sem dispensar atenção aos lugares antes de fazer as usuais fotografias.

Estava em um museu em Paris e havia muitos turistas de todas as nacionalidades, principalmente chineses, que fotografavam sem parar, além de filmarem esculturas e quadros sem ao menos parar alguns minutos para admirá-los. Eu queria ver com calma as obras, mas o ambiente dificultava, o que era paradoxal. Aquelas pessoas não pareciam estar vivendo uma experiência com algum sentido. 
Elas não olhavam nada, como poderiam tirar algum sentido daquela visita? Eu estava tentando absorver algo, conversando com as pessoas da minha família, mas aquilo parecia sem sentido.

A aluna manifestava certa angústia. O contato com um fluxo intenso de turistas de várias nacionalidades em um museu constituiu um aspecto de difícil apreensão para ela, algo próximo de um estranhamento cultural com relação aos turistas (principalmente aos orientais, mais numerosos) que reverberou em si própria: deslocada e bloqueada na vivência em um museu.

Os professores presentes também dialogaram, comentando sobre um relato de viagem de David Foster Wallace (2012), que é um tipo de contrarrelato, pelo tom crítico com o qual narra um cruzeiro marítimo, destacando a artificialidade de alguns formatos de viagem. Discutiram, também, possibilidades de a viagem acontecer dentro da cidade em que se vive, por dentro das periferias, por cidades próximas, por meio de passeios descompromissados que permitam a valorização da própria cidade. A presença e a participação dos professores constituíram um ponto de reflexão balizador para o posicionamento dos alunos em geral.

Os diálogos continuaram até que foi criado um ambiente para a prática programada, a qual foi realizada e seguida de um momento de compartilhamento do que foi produzido pelos participantes. Alguns representaram as experiências de viagem por meio de desenhos, conforme se vê (Figura 1).

Figura 1: Viajar é como trocar a roupa da alma

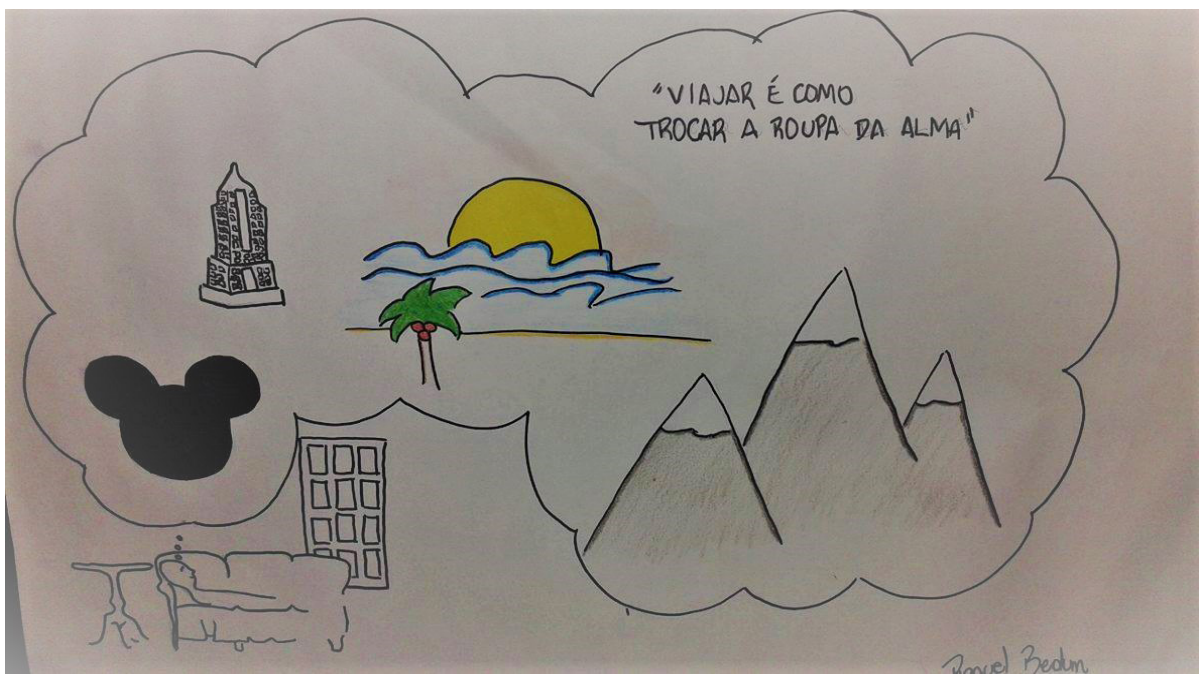

Fonte: foto produzida por professora e encaminhada para mim por e-mail, em abril de 2017.

A relação entre o sujeito e o mundo das viagens foi representada a partir da escolha de símbolos diversos que agregam a diversidade de paisagens, os ambientes de lazer e as grandes cidades em um espaço produzido por um devaneio imaginativo. 
A nuvem da imaginação, comum nas representações gráficas das histórias em quadrinhos e dos desenhos animados, foi o recurso utilizado pelos alunos para ilustrar o debate sobre produção de sentido para viagens, reunindo uma gama de elementos presentes na discussão e, certamente, outros símbolos que habitam a imaginação de cada aluno.

O desenho do homem deitado no sofá, entre uma pequena mesa e a janela, foi reproduzido da capa de um dos livros que apresentei aos alunos e que circulou durante a oficina prática, o Viagem à roda do meu quarto, de Xavier de Maistre (2008). É perceptível uma identificação do grupo com o livro, uma paródia da literatura do gênero viagens, e é interessante perceber a composição sobre viagem como algo a ser imaginado. A escolha do interior da casa como espaço para o viajante sonhar, imaginar ou mesmo idealizar uma viagem, de modo a trocar a roupa da alma, ou seja, buscar uma renovação pessoal.

Buscar a renovação pode ser um objetivo superficial, que oblitera as reais necessidades de viajar, já que mantém o viajante preso em um ciclo que se repete. Assim se expressou um dos alunos por meio de uma poesia declamada:

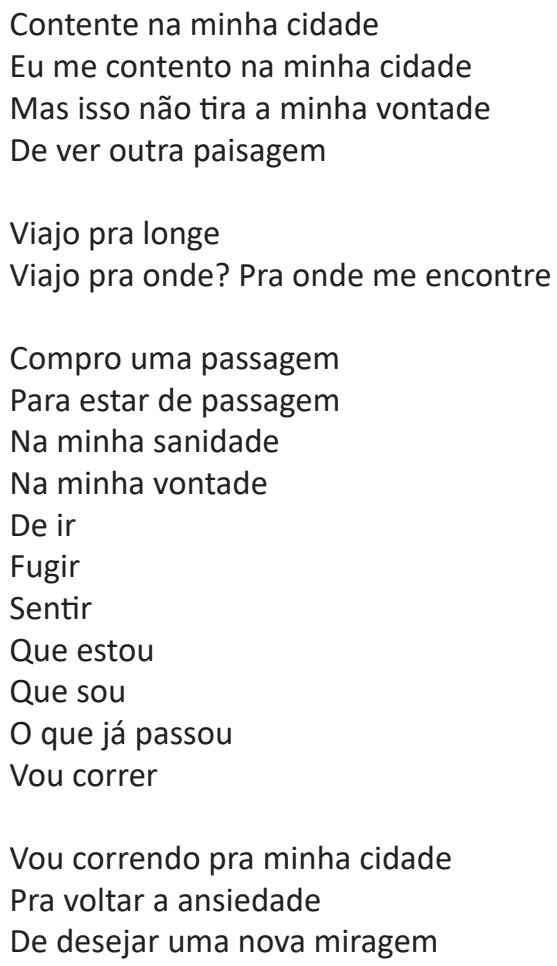

Um desejo mal-definido e mal-elaborado: um impulso. A vontade de ver algo diferente, de buscar, mas, mais ainda, de fugir por meio da compra da viagem que permite o distanciamento do tédio que anestesia; não é propriamente de um sentimento ruim que produz o desejo de sair da cidade, mas do comodismo de estar contente ou consternado. É preciso deslocar-se para sentir-se, para sentir que se é e que se está. 
O poema do aluno produz a noção da viagem como ciclo vicioso, já que o deslocamento é vivido de modo banal e pouco consciente, na medida em que o viajante responde ao impulso de se deslocar com a compra da passagem, ao invés de elaborá-lo. Onde estarão os reais motivos para viajar? Onde estará esse sujeito-viajante, inconsciente acerca de si mesmo, sobre seus desejos? O movimento não contempla o viajante integralmente, apenas parte dele, o corpo, as sensações, de modo que ele passa pela vontade sem transformá-la.

A viagem se torna um caminho percorrido com pressa, por um viajante que volta o mesmo, apenas mais cansado. Como o deslocamento se dá com o desencaixe entre o sujeito e o tempo vivido, a viagem não se torna experiência, já que a disponibilidade do sujeito para se "abrir" e para significar a vivência é insuficiente. 0 tempo para esse viajante está sempre adiantado: um pouco à frente do que deveria ser, pois é novamente a ansiedade, e não o desejo elaborado, que produz a vontade de um novo deslocamento.

Além da declamação do poema, que produziu uma conversa entre todos os presentes, recebi outras representações, das quais destaco um texto intitulado Viagem. Trata-se de um ensaio em que uma aluna comenta, com dois pontos, as reflexões que produziu:

$1^{\circ}$ ponto: A minha última viagem me fez descobrir como além de conhecer um espaço novo/uma cultura/pessoas novas, acabamos tendo contato mais profundo com as pessoas com quem viajamos, às vezes chega a ser até espiritual e às vezes acabamos descobrindo quem são realmente as pessoas (mesmo com alguém que já temos contato).

O aspecto destacado da vivência da autora é um tipo de descoberta sobre os encontros de viagem. A experiência é vivida em companhia e compreende também transformações nos laços do viajante com os companheiros de viagem. As reflexões desse sujeito, comuns àqueles que viajam com outras pessoas, explicitam que as fronteiras entre o viajante e o outro não correspondem apenas às diferenças socioculturais que podem ser suspensas em viagem a partir da concepção comum de aproximação geográfica/espacial. O outro do viajante pode ser entendido como uma categoria que funciona como um aporte móvel dinamizador do processo vivenciado: ora é encontrado em si mesmo ora naqueles que cruzam o caminho dele ora naquele que está "ao lado". A autora lembra que, em viagem, os encontros podem ser seguidos de desencontros, e vice-versa, já que a descoberta de "quem são realmente as pessoas" pode levar à decepção ou à criação e ao aprofundamento de vínculos.

A autora traz um segundo ponto para a reflexão:

$2^{\circ}$ ponto: Viajar me lembra o mar, talvez porque em Minas não tenha e sempre que temos oportunidade vamos ver uma água nova. E eu me sinto vulnerável no mar, como se a qualquer momento aquela natureza gigante azul que não me deixa enxergar ou respirar fosse me engolir. Gosto de ir no mar sempre que possível para sentir a mortalidade. 
A escolha do mar como imagem de comparação com a experiência de viagem perpassa a identificação da autora como mineira, cuja natureza relaciona-se às montanhas e à "terra firme", radicalmente oposta à natureza do litoral. Com lirismo, a aluna expressa a vivência da alteridade a partir da experiência que é expandida a um grau de intensidade que abrange o limiar entre a vida e a morte.

\subsection{Exercícios de fazer crônicas de viagem: graduandos da Universidade de Coimbra}

A palestra "O que dizem as crônicas sobre a experimentação do viajante? Reflexões sobre a viagem em Portugal e no Brasil" foi realizada durante uma aula da disciplina Geografia Cultural, ministrada pelo professor João Luís J. Fernandes. Os moldes da apresentação ocorreram no formato palestra e, ao contrário do que aconteceu no Instituto Casa Viva, a participação foi escassa. A parte prática, de produção de crônicas de viagem, contudo, foi mais substantiva e resultou em alguns relatos escritos.

Durante a palestra, foi proposto um momento de reflexão sobre a viagem como experiência habitualmente expressa sob formas narrativas, destacando a relação entre viajar e contar a viagem, atividades tão próximas que se misturam. Chamei a atenção para a presença de tal relação em conversas informais, em relatos escritos em livros ou em blogs, acompanhados de fotografias ou de pequenas frases "soltas". Tratei a narração como mecanismo de estruturação da memória e de reflexão sobre os elementos da vivência que agrupamos com a denominação de viagem. Relacionei o ato de narrar com o imaginário ocidental, abordando livros famosos da literatura de viagem e, para aprofundar a reflexão, propus discutir a narração de viagens enfatizando a crônica.

Debati a crônica como um gênero e, no caso da literatura relacionada à viagem, como modalidade que resulta de uma tradição em vários países, inclusive em Portugal e no Brasil. Convidei os alunos a considerarem a crônica como um tipo de molde que potencializa e normatiza a experiência de viajantes comuns. Para desenvolver a reflexão, debati a ideia de experimentação como processo de criação da experiência que abraça a vivência e permite a construção de sentido para o próprio viajante e para outras pessoas.

A apresentação foi desenvolvida até que eu projetei trechos de crônicas de viagem escritas por autores com livros publicados e por pessoas com perfis em redes sociais. Apresentei cinco crônicas: "A vontade e o mundo", de José Luis Peixoto; "Geografia das amizades", de Gonçalo Cadilhe; uma crônica sem título que tratava da Noruega, de Cora Rónai; "Histórias de viagem", de Marília Saldanha; e uma crônica de Luiz Gabriel Lopes intitulada ":: o inevitável relato do viajante novamente encantado pela estrada $\&$ em seus primeiros minutos de Wi-Fi ::" .

Dos autores, dois são conhecidos escritores portugueses, José Luis Peixoto e Gonçalo Cadilhe, uma é jornalista brasileira, Cora Rónai, e Luiz Gabriel Lopes e Marília Saldanha são músico e pesquisadora, respectivamente. Enquanto os autores portugueses e a jornalista brasileira publicaram os textos em meios de comunicação eletrônicos, os dois últimos compartilharam os escritos no Facebook e fazem parte da mesma rede social que eu, por isso tive acesso a tais textos. 
Selecionei esse material a partir da leitura de trechos que considerei interessantes para pensar nos caminhos narrativos da crônica que organizam um narrador viajante, mediante uma identidade assumida, e que representam os limites da experiência de viagem.

Nas crônicas de Gonçalo Cadilhe, Luiz Gabriel Lopes e Cora Rónai, há elementos que os posicionam como viajantes aptos a narrar e, a partir de tal posicionamento, que é associado a algum elemento identitário, as observações de viagem desses escritores são direcionadas. Gonçalo Cadilhe menciona duas mulheres mochileiras que encontrou em viagens e pensa as vantagens de viajar de "modo feminino". Posiciona-se, na citada crônica, como um viajante de outro gênero e explora essa categoria para fazer as observações. Na crônica de Cora Rónai, publicada originalmente no Jornal O Globo, como ela informa ao final do texto compartilhado no blog, ela retrata a Noruega como uma brasileira ou latino-americana:

Por onde quer que se ande na Noruega o altíssimo IDH é visível, quase palpável. Não há nada remotamente parecido com uma favela, as calçadas não têm buracos, as casas são bem conservadas e não têm pichações nas paredes, a população é saudável e veste-se bem, os carros são novos e bons.

A associação da autora como viajante brasileira é feita de modo não tão explícito, mas suficiente para localizar um "lugar de fala". Outra marcação usada foi a do clima:

Em suma: assim como as nossas estações variam pouquíssimo ao longo do ano, parece que as deles também não mudam muito. Poderíamos até ser - e não só no clima - verso e reverso da mesma medalha [...].

É claro que, no horizonte de criação da autora, está situado o público leitor, o público de um jornal que possui grande audiência no Brasil. É posicionando-se como observadora que ela divide a identidade comum com o público, no caso, de leitores brasileiros, e que a autora pode construir a própria representação sobre a Noruega, feita em poucas linhas e baseada em pares de oposição simplistas. As estratégias do discurso da jornalista evidenciam uma posição de comparação que reforça estereótipos baseados em convenções, como o posicionamento da Noruega acima do Brasil no mapa-múndi, as ideias de determinismo geográfico usadas para justificar um estado de suposta inferioridade sociocultural do Brasil com relação aos países europeus. Gostaria de destacar um ponto específico do discurso da cronista: o reconhecimento do eu-narrador como jornalista que publica em um grande veículo midiático do Brasil e que utiliza a identidade de brasileira para se posicionar como viajante.

Luiz Gabriel Lopes, em sua crônica, representa uma viagem ao Amazonas feita de barco e se posiciona como um brasileiro que viaja para dentro do próprio país. Assume a identidade de brasileiro do Sudeste, identidade "sudestina", a partir da qual organiza as impressões para o público que possui na rede social: 
[...] são muitas milhas para atestar novamente diante dos olhos a complexidade desse descabimento territorial chamado Brasil, que se esboça no encontro com modos de vida e visões de mundo tão concretamente outros, ainda que marcados pela massacrante hegemonia midiática sudestina que não dá trégua nem durante as áreas mais desertas do caminho.

Já nas crônicas de José Luis Peixoto e Marília Saldanha, não é a identidade cultural a chave da criação da crônica de viagem, mas a exploração do sentido do percurso. "Um dia, vou cansar-me de querer conhecer o mundo", diz José Luis Peixoto.

Às vezes, parece-me que conheço demasiados caminhos. Para ir a certos lugares, não tenho de pensar. [...]. Conheço tão bem esses caminhos que quase me surpreendo quando chego ao destino. Às vezes, quero ir a lugares ligeiramente diferentes, distraio-me por um momento e, quando reparo, já estou a fazer esses caminhos de novo. $O$ hábito enganou-me.

O autor explora o ato de percorrer como hábito, para refletir sobre a viagem como ressignificação da ação de percorrer caminhos, como uma ruptura do cotidiano:

Sim, um dia vou cansar-me de querer conhecer o mundo, mas hoje ainda não é esse dia. Tenho os sentidos ávidos por tudo aquilo que me espera. Não tenho qualquer receio de estar sozinho, sem mapa, no centro de Singapura, numa avenida de Caracas, diante de uma paisagem do Alasca. Anseio por esse momento.

O ato de viajar é uma forma de suspender o poder do hábito, retirar o conforto e, por consequência, promover a surpresa em contato com o desconhecido que é expresso a partir da projeção da imagem do viajante em percurso por lugares em que não pode se localizar facilmente, "sem mapa".

Já a crônica de Marília Saldanha explora a relação intuitiva do viajante com os caminhos:

Sabe? não tenho escolhido lugares e traçado rotas, nada tenho planejado, fora alguns nortes, vez ou outra, tenho me deixado atrair pelos labirintos, pelas ruelas sombrias [...] quero a sede de vida dos viajantes, o perfume das flores desta cidade, o encontro, a curva, a escadaria, a ladeira, o desconhecido. Sabe?

A estratégia usada pelos autores consiste em abordar o sentido do percurso como elemento fundamental relacionado ao desconhecido, por meio da exploração de recursos sinestésicos. A viagem é concebida como um exercício da sensibilidade, e são as sensações a ela associadas que permitem ao viajante construir um sentido particular para as vivências deles. A "sede dos viajantes", os "sentidos ávidos" por viajar e o "perfume das flores da cidade" são dimensões da sensibilidade associadas 
ao percurso pelo desconhecido e perpassadas pelo prazer, e não pelo medo. Como aponta José Luis Peixoto, não há receio em estar em lugares que não conhece, ideia semelhante à que Marília Saldanha indica ao afirmar que, além de não sentir medo, sente-se atraída pelas sombras e pelos labirintos.

Os dois viajantes, ao assumirem-se como praticantes de percursos por lugares para além dos familiares, conectam-se aos leitores, os quais, supõe-se, possuem certa intimidade com esse exercício de viajar balizado pelas sensações despertadas com os itinerários. Contudo, como não expõem as próprias identidades na construção das imagens de caminho e de percurso, eles limitam a reflexão. É importante comentar que, com um pouco de autorreflexão acerca da identidade, a questão dos medos seria balizada por outros parâmetros, como classe social, nível educacional, já que os medos de se estar em determinado local estão para além da questão geográfica, de localização, mas são relativos aos cerceamentos impostos aos sujeitos - marcados pelas histórias deles e, infelizmente, alvo de estereótipos e de preconceitos.

Da mesma forma, é possível pensar em quantas Singapuras e quantas paisagens do Alasca podem ser encontradas, algumas certamente mais violentas e inóspitas que outras. Ou mesmo, se a viajante brasileira estaria explorando a atração pelo labirinto caso não estivesse em uma cidade europeia, mas em uma brasileira. A questão, portanto, sempre extrapolará medos e desejos concebidos de modo universal e descontextualizado.

Das crônicas abordadas, sobressai a relação entre autores e leitores como uma rede de significados de viagem que é retomada pelo discurso, por meio de alguns mecanismos-chave que busquei identificar e destacar durante a palestra realizada: a identidade cultural e os sentidos associados à atividade de percorrer. Essa rede de significados é comum a autores e leitores, na medida em que ambos são viajantes com alguma familiaridade com o ato de viajar e, muitas vezes, já conhecem os lugares abordados nos textos. Há de se considerar, também, que o leitor possa ser "imóvel", ou seja, limitado na mobilidade por diversas razões e em diversos níveis, mas mesmo esse leitor não é indiferente ou alienado de práticas de percurso associadas com a viagem e representadas em outras linguagens: no cinema, na televisão, na pintura, etc.

Após a análise das crônicas, propus aos alunos que escrevessem uma reflexão, em formato de crônica, a partir de alguma experiência de viagem. Sugeri um limite de 15 linhas para a realização do exercício. Os textos abordaram assuntos diversos, referenciando grandes cidades e, em menor quantidade, a relação íntima da viagem para o autor.

Em A cidade maravilhosa, a autora realiza um elogio ao Rio de Janeiro, explicitando impressões positivas sobre a cidade considerada por ela o coração do Brasil, por haver muita alegria decorrente das festas dos brasileiros. Para se expressar, serve-se da categoria maravilha/maravilhoso, categoria presente em textos da literatura de viagens, como possibilidade para representar as impressões:

Como exprimir o que esta cidade tem de único sem a visitar? Eu não consigo escrever tudo o que senti e que vivi no Rio de Janeiro. Agora percebo porque tem a alcunha de cidade maravilhosa, realmente tudo o que se passa é maravilhoso. O samba que se ouve 
nas ruas, a alegria das pessoas, a energia positiva que se sente quando se aterra no aeroporto e sais do avião, a comida excelente e as praias lindíssimas, já para não falar nas paisagens.

Os viajantes tendem a compartilhar a dimensão apreensível dos lugares durante a experiência de viagem, sem ponderar que o que viveram é limitado pelo tempo de permanência e por outras fronteiras, como aquelas presentes nos lugares considerados turísticos. Os limites da viagem raramente são incorporados pelo narrador. No trecho acima reproduzido, a autora generaliza, "[...] tudo o que se passa é maravilhoso", mencionando a experiência turística que viveu durante um tempo de permanência restrito, sem relativizar as considerações que faz. A crônica da aluna, um relato escrito em sala de aula, é pouco crítica e nos leva a pensar em que medida a estrutura da crônica em geral, por ser associada a observações breves do cotidiano, ao humor e à leveza, é pouco afeita à crítica.

O tom crítico se fez presente em outro texto:

\begin{abstract}
Cheguei a Leiria à procura do Eça e da Leiria do Eça. Encontrei-o principalmente nas paredes: grafitado, pintado, citado. Mas essas paredes também estavam degradadas, desgastadas, na sombra de uma cidade que não precisa do Eça, de uma população que se senta numa esplanada a tomar café e não sabe que a estátua ao lado é de um autor que descreveu e viveu a sua cidade.
\end{abstract}

A autora do segundo texto revela o motivo da viagem que fez e o desconforto gerado por perceber que, entre a cidade de Leiria narrada por Eça de Queirós e a atual cidade, há uma distância. Ela percebe também uma incoerência entre a consagração de um nome de modo formal como ação relacionada à consagração do patrimônio público, que motiva a criação de uma estátua e afixação de frases do autor pela cidade, porém há uma desvalorização e mesmo desconhecimento por parte da população sobre o autor.

O que resta dessa Cidade de Eça? As paredes. Ainda há "beatas" e "cuscas" nas janelas dessas paredes, as igrejas ainda lá estão; mas escondidas nas ruas paralelas ao pulmão jovem, despreocupado, cheio de oportunidades de uma Praça que tem o nome de um autor que ninguém conhece, mas que refere todos os dias ao marcar novo encontro.

Por fim, a autora parece descobrir as razões de tal descompasso, a qual seria uma questão geracional que ela explica por meio de imagens de uma cidade em camadas, cujas camadas mais jovens dominam a paisagem. A autora, contudo, não explicita o percurso que ela fez por Leiria, nem a relação que possui com a cidade, opta por criar uma crônica próxima ao ensaio, em um formato que the permite organizar percepções sobre uma cidade, mas que não demonstra a relação estabelecida com o lugar como viajante. 
Nem todos os alunos se distanciam dos lugares retratados nas crônicas que escrevem. É o caso de um texto sobre Nova lorque:

Começou de uma maneira "random" com um engano no metroô à chegada de uma capital do mundo... New York. Pela primeira vez, posso dizer que me senti em casa, que me identifiquei totalmente com uma cidade. $\mathrm{O}$ cheiro e aspecto industrial do metrô mais conhecido do mundo fez-me vibrar, literalmente [...].

O autor expressa uma sensação única, só possível por meio de uma viagem: a sensação de se sentir em casa pela primeira vez na vida. A identificação com um lugar é um constructo de sentido de viagem comum na literatura do gênero, como no diário de Gustave Flaubert, destacado por Alain de Botton (2012), que era um francês apaixonado pelo oriente e, mais exatamente, pelo Egito. As sensações de não pertencer à pátria natal e de visitar um lugar e sentir-se parte dele são comum ao autor da crônica acima e a outros viajantes.

O sentido da viagem é expandido no relato de um aluno intercambista cuja viagem representada compreende um período maior de tempo, distinguindo-se da noção de visita e passeio. $O$ aprofundamento nas reflexões sobre o sentido de viagem abrange aspectos relacionados ao conceito de vida.

Há exatamente dois anos que eu resolvi pegar a estrada e sair a viajar. Já nem sei quando que a minha viagem vai acabar, embora eu vá voltar para minha cidade de origem o mês que vem. Não sabia o que esperar quando resolvi sair para morar no Rio de Janeiro dois anos atrás. Dois anos depois compreendo que não deve-se esperar nada das viagens, que a única importância é ter aquela pré disposição para absorver e deixar que os lugares, as pessoas e as experiências que vão passando, alterem a nossa visão e percepção do mundo. Sempre pensei na viagem como algo físico, externo, mas agora posso compreender que a única viagem real é interna, e está dentro de nós.

\section{Considerações finais}

A paixão pelos lugares, o sonho, a imaginação, o prazer de sentir-se vivo, a vontade de comungar algo muito simples. A viagem mobiliza sentimentos, dispara um processo sensível para o qual os viajantes parecem não estar preparados. São sentimentos pouco nomeados, talvez pouco conhecidos.

Os viajantes dessas experimentações, os estudantes que aceitaram o convite de pensar sentidos de viagem, estão familiarizados tanto com a ideia de viagem quanto com o imaginário das viagens. Seriam, todavia, pouco experimentados na prática de relatar e criar sentido para o que vivenciaram. Os mais experimentados, os viajantes "profissionais", não superam algumas questões, pelo contrário, parecem usar a crônica justamente por ser um tipo de comunicação breve, que não exige deles um aprofun- 
damento. Ao aderirem ao formato convencional da crônica, há um esvaziamento de potencialidades. Os cronistas, por serem os mais experimentados nesse tipo de textos, não seriam os mais preparados para estimular a reinvenção de barreiras, a criação de um olhar que se aproxima e que conduz o outro para a experiência que viveram?

A estrutura da crônica por si só não garante a criação de uma representação prenhe de significados, talvez consista em um grande desafio para os viajantes, já que convida a dizer muito com poucas palavras. Os estudantes, mais abertos a experimentar a elaboração dos relatos que os profissionais, mostraram que, com poucas palavras, é possível deslocar a viagem de sentidos desgastados, banalizados e inspirar leitores, como nós.

\section{Referências}

BOTTON, Alain. A arte de viajar. Rio de Janeiro: Intrínseca, 2012.

CADILHE, Gonçalo. Encontros marcados. 3. ed. Lisboa: Clube do Autor, 2014.

CADILHE, Gonçalo. 1 km de cada vez. 8. ed. Alfragide: Oficina do Livro, 2016.

HOMERO. Odisseia. 2. ed. São Paulo: Atena, 1957.

MAISTRE, Xavier. Viagem à roda do meu quarto; seguido de Expedição noturna à roda do meu quarto. São Paulo: Estação Liberdade, 2008.

PESSOA, Fernando. Livro do desassossego. 2. ed. São Paulo: Companhia das Letras, 2002 [1982].

POLO, Marco. O livro das maravilhas: a descrição do mundo. Porto Alegre: L \& PM Editores, 1999.

QUINTANA, Mário. Baú de espantos. 2. ed. São Paulo: Globo, 2006.

RÓNAl, Cora. Impressões de viagem II. In: Blog Cora Rónai, 2 set. 2010. Disponível em: https://cronai.wordpress.com/2010/09/02/impressoes-de-viagem-ii/. Acesso em: 10 nov. 2019.

WALLACE, David Foster. Ficando meio longe do fato de estar longe de tudo. São Paulo: Companhia das Letras, 2012. 


\section{Informações complementares}

Financiamento

Bolsa de Doutorado Capes, Bolsa de Doutorado Sanduíche no Exterior Capes.

Contribuição de autoria

Concepção e elaboração do manuscrito: Júlia Fonseca de Castro.

Coleta de dados: Júlia Fonseca de Castro.

Análise de dados: Júlia Fonseca de Castro.

Discussão dos resultados: Júlia Fonseca de Castro.

Revisão e aprovação: Júlia Fonseca de Castro.

Preprint, originalidade e ineditismo

O artigo é original, inédito e não foi depositado como preprint

Consentimento de uso de imagem

A autora possui autorização explícita para divulgação de imagem de terceiros.

Aprovação de Comitê de Ética em Pesquisa

Não se aplica.

Conflito de interesse

Não há conflitos de interesse.

Conjunto de dados de pesquisa

Não há dados disponibilizados.

Licença de uso

Os autores cedem à Revista Pesquisa e Debate em Educação os direitos exclusivos de primeira publicação, com o trabalho simultaneamente licenciado sob a Licença Creative Commons Attribution (CC BY) 4.0 International. Esta licença permite que terceiros remixem, adaptem e criem a partir do trabalho publicado, atribuindo o devido crédito de autoria e publicação inicial neste periódico. Os autores têm autorização para assumir contratos adicionais separadamente, para distribuição não exclusiva da versão do trabalho publicada neste periódico (ex.: publicar em repositório institucional, em site pessoal, publicar uma tradução, ou como capítulo de livro), com reconhecimento de autoria e publicação inicial neste periódico.

Publisher

Universidade Federal de Juiz de Fora (UFJF), Faculdade de Educação (FACED), Centro de Políticas Públicas e Avaliação da Educação (CAEd), Programa de Pós-Graduação Profissional em Gestão e Avaliação da Educação Pública (PPGP). Publicação no Portal de Periódicos da UFJF. As ideias expressadas neste artigo são de responsabilidade de seus autores, não representando, necessariamente, a opinião dos editores ou da universidade.

Editores

Frederico Braida; Liamara Scortegagna; Wagner Silveira Rezende.

Formato de avaliação por pares

Revisão duplamente cega (Double blind peer review). 


\section{Sobre a autora}

\section{Júlia Fonseca de Castro}

Graduada em Turismo (UFMG). Mestra em Geografia (UFMG). Doutora em Geografia (UFMG).

Currículo Lattes: http://lattes.cnpq.br/2896064194733123 